\title{
Characterization of the external female genitalia of six species of Triatominae (Hemiptera: Reduviidade) by scanning electron microscopy
}

\author{
João Aristeu da Rosa ${ }^{1}{ }^{+}$, Vagner José Mendonça ${ }^{2}$, Cláudia Solano Rocha ${ }^{1}$, Sueli Gardim¹, Mario Cilense ${ }^{3}$ \\ 1'Departamento de Ciências Biológicas, Faculdade de Ciências Farmacêuticas ${ }^{3}$ Departamento de Físico-Química, Instituto de Química, \\ Universidade Estadual Paulista-Araraquara, Rod. Araraquara-Jaú km 1, 14801-902 Araraquara, SP, Brasil ${ }^{2}$ Instituto de Biologia, \\ Departamento de Biologia Animal, Universidade Estadual de Campinas, Campinas, SP, Brasil
}

By macroscopic and microscopic dorsal side observation, it was noted that the IX and X segments of two species each of Panstrongylus and Triatoma terminate in an elongated way, whereas they terminate abruptly in the two species of Rhodnius. Scanning observation of the dorsal, ventral, lateral and posterior sides of the female genitalia of Panstrongylus herreri, Panstrongylus megistus, Rhodnius colombiensis, Rhodnius prolixus, Triatoma infestans and Triatoma vitticeps revealed that these six species are generally and specifically distinguished based on these elements. We describe several components that distinguish P. herreri from P. megistus: four on the dorsal side: the VII, VIII, IX and X segments, on the ventral view, three: VII sternite, VIII gonocoxite and VIII gonapophyse, on the lateral view one character, VIII gonocoxite and on the posterior view three characters: VIII and IX gonocoxite and XI gonopophyse. Comparing R. colombiensis and R. prolixus, there were three distinct characters on the dorsal side: the VII, VIII and X segments, on the ventral view three characters: the IX and X segments and VIII gonocoxite and on the posterior view four characters: the VIII, IX, X segments and VIII gonapophyse that distinguish the two species. $\mathrm{T}$. infestans and T. vitticeps have four different characters on the dorsal side: the VII, VIII, IX and X segments, on the ventral view four characters: the VII and X segments, VIII gonocoxite and VIII gonapophyse, on the lateral view two characters, IX and X segments and on the posterior view four characters: the IX and X segments, VIII gonocoxite and VIII gonapophyse that distinguish the two species. Examination of the external female genitalia of six triatomine species by scanning suggests that these components are useful for taxonomical studies.

Key words: Triatominae - taxonomy - external female genitalia

Triatominae responsible for the transmission of Trypanosoma cruzi to humans and to a group of seven orders, 24 families and 150 species of domestic and wild vertebrates (WHO 2007). Although the incidence of Chagas disease has decreased, there are presumably 11 million people infected in the Southern Cone countries (Moncayo \& Silveira 2009). Thus, studies on triatomines must continue, especially considering the wide distribution of these species in the Neotropical region, which includes Brazil.

There are 140 species of Triatominae (Rocha et al. 2009) and all of them are potential vectors of T. cruzi in the five nymphal instar stages and as adults. The characterisation of such species is necessary so that control actions can be taken and, additionally, they are important to phylogenetic and taxonomic studies.

Financial support: PADC/FCF/UNESP/Araraquara (2009/10-II), Fapesp (2009/52137-4)

+Corresponding author: rosaja@fcfar.unesp.br

Received 24 August 2009

Accepted 12 March 2010
The distinction of Triatominae is based on morphological characteristics, such as the male genitalia, a marker that has been largely used (Lent \& Wygodzinsky 1979, Jurberg et al. 1998, Papa et al. 2002), although more recent descriptions have not used it (Costa et al. 2006, Galvão \& Angulo 2006, Costa \& Felix 2007). Morphometric studies are also utilised, such as egg mensuration (Santos et al. 2009).

The female genitalia and its appendages are frequently used for the distinction of some vectors, as with the spermatheca in many species of Phlebotominae (Marcondes et al. 1998, Galati 2003), but they have not been recently used in the case of Triatominae. Publications on the female genitalia of Triatominae by Lent (1948), Abalos and Wygodzinsky (1951), Sherlock and Serafim (1967) or Lent and Jurberg (1969); all of these studies were carried out through dissection and optical microscopy. Lent and Wygodzinsky (1979) explain that, "the genitalia of the female are rather uniform and furnish few taxonomic characters".

This paper describes the external female genitalia and the VII, VIII, IX and X segments of three genera by scanning electron microscopy (SEM). The species studied, Panstrongylus megistus, Panstrongylus herreri, Rhodnius prolixus, Rhodnius colombiensis, Triatoma infestans and Triatoma vitticeps, showed clear distinctions regarding the female genital characters observed on the dorsal, ventral, lateral and posterior sides. 


\section{MATERIALS AND METHODS}

This research included 32 specimens of triatomines from 17 colonies that are kept in the Insetário de Triatominae da Faculdade de Ciências Farmacêuticas, Universidade Estadual Paulista (UNESP)-Araraquara.

A different number of specimens per species was utilised: two of $P$. herreri (Colônias de Triatominae Araraquara - CTA 118, 187), four of $P$. megistus (CTA 102, 146, 209, 257), 13 of $R$. prolixus (CTA 003, 015, 029, 033, $046,048,205$ ), four of $R$. colombiensis (CTA 212), five of T. infestans (CTA 007, 064) and four of T. vitticeps (CTA 041) (Table I).

After euthanasia, the triatomines were transversely cut in the 6th abdominal segment, washed, dehydrated in an alcohol series and oven-dried at $50^{\circ} \mathrm{C}$, according to Rosa et al. (2005). Subsequently, they were fixed on aluminium stubs by the 6th abdominal segment so that the terminal portion formed an angle of $90^{\circ}$ with the support base. Afterwards, sputtering metallisation was performed for $2 \mathrm{~min}$ at $10 \mathrm{~mA}$. Then the dorsal, ventral, lateral and posterior sides were examined by a Topcon SM 300 SEM at the Instituto de Química, UNESP-Araraquara.

\section{RESULTS}

Dorsal side - Macroscopic and microscopic examination of the dorsal side of $P$. herreri, $P$. megistus, $T$. infestans and T. vitticeps shows that their last abdominal segments end in an elongated way, while in R. colombiensis and $R$. prolixus such structures end abruptly.
The use of SEM led to the finding that there is a clear separation between the VII and VIII tergites in P. herreri, whereas such separation is not as pronounced in $P$. megistus, especially in the central portion, where the two segments appear together. P. megistus has the IX tergite and the $\mathrm{X}$ segment, which are more elongated and have a conical shape. Although these structures are also elongated in $P$. herreri, they do not have a clearly conical shape (Fig. 1A, B).

In $P$. herreri and $P$. megistus, the IX tergite stands completely separated from the X segment. $P$. herreri has the two lateral borders of the IX tergite segment raised, while in P. megistus this segment is flat. In P. herreri, the IX tergite is half the length of the same structure in P. megistus, but both have the same width. The X segment is 1.5 times larger in length in P. megistus than in P. herreri (Fig. 1A, B).

The line separating the VII and VIII tergites is curved and continuous in $R$. prolixus, but in $R$. colombiensis it has an inflection in the central part. The final portion of the X segment is large in $R$. colombiensis and narrow in $R$. prolixus. The edge of the IX tergite of $R$. prolixus has $1+1$ protuberances that do not exist in $R$. colombiensis (Fig. 1C, D).

T. infestans shows $1+1$ callosities next to the dividing line between the VIII and VII tergites, as well as between the IX tergite and the X segment. These callosities are not seen in T. vitticeps. Lateral portions of the IX tergite have an expanded shape in $T$. infestans, a feature

TABLE

Species, colonies and origin of the triatomines used for the characterization of female genitalia by scanning electron microscopy

\begin{tabular}{|c|c|c|c|}
\hline Species & Colonies & Origin & Initiated \\
\hline \multirow[t]{2}{*}{ Panstrongylus herreri } & CTA 118 & Vale do Rio Utoubamba, Peru & 25 Oct 1984 \\
\hline & CTA 187 & Instituto Oswaldo Cruz-Fiocruz, Rio de Janeiro, Brazil & 17 Jan 1997 \\
\hline \multirow[t]{4}{*}{ Panstrongylus megistus } & CTA 102 & $\begin{array}{l}\text { Faculdade de Medicina, Universidade de São Paulo (FMUSP), } \\
\text { São Paulo (SP), Brazil }\end{array}$ & 2 Aug 1984 \\
\hline & CTA 146 & Boca da Mata, Alagoas, Brazil & 11 Feb 1985 \\
\hline & CTA 209 & Sítio Carandá, Araraquara, SP, Brazil & 11 Apr 2000 \\
\hline & CTA 257 & Sítio Carandá, Araraquara, SP, Brazil & 16 Oct 2007 \\
\hline \multirow[t]{7}{*}{ Rhodnius prolixus } & CTA 003 & Bogotá, Colombia & 15 Dec 1976 \\
\hline & CTA 015 & Colômbia & 5 Oct 1972 \\
\hline & CTA 029 & FMUSP, SP, Brazil & 9 Aug 1982 \\
\hline & CTA 033 & Bogotá, Colombia & 15 Dec 1976 \\
\hline & CTA 046 & Costa Rica & 25 May 1983 \\
\hline & CTA 048 & Venezuela & 25 May 1983 \\
\hline & CTA 205 & Ortiz Caseiro, Edoguarica, Venezuela & 5 Sep 1999 \\
\hline Rhodnius colombiensis & CTA 212 & Tolima, Colombia & 15 Feb 2001 \\
\hline \multirow{2}{*}{ Triatoma infestans } & CTA 007 & Mambaí, Goiás, Brazil & 28 Feb 1980 \\
\hline & CTA 064 & Peru & 5 Aug 1983 \\
\hline Triatoma vitticeps & CTA 041 & Minas Gerais, Brazil & 25 Jul 1968 \\
\hline
\end{tabular}



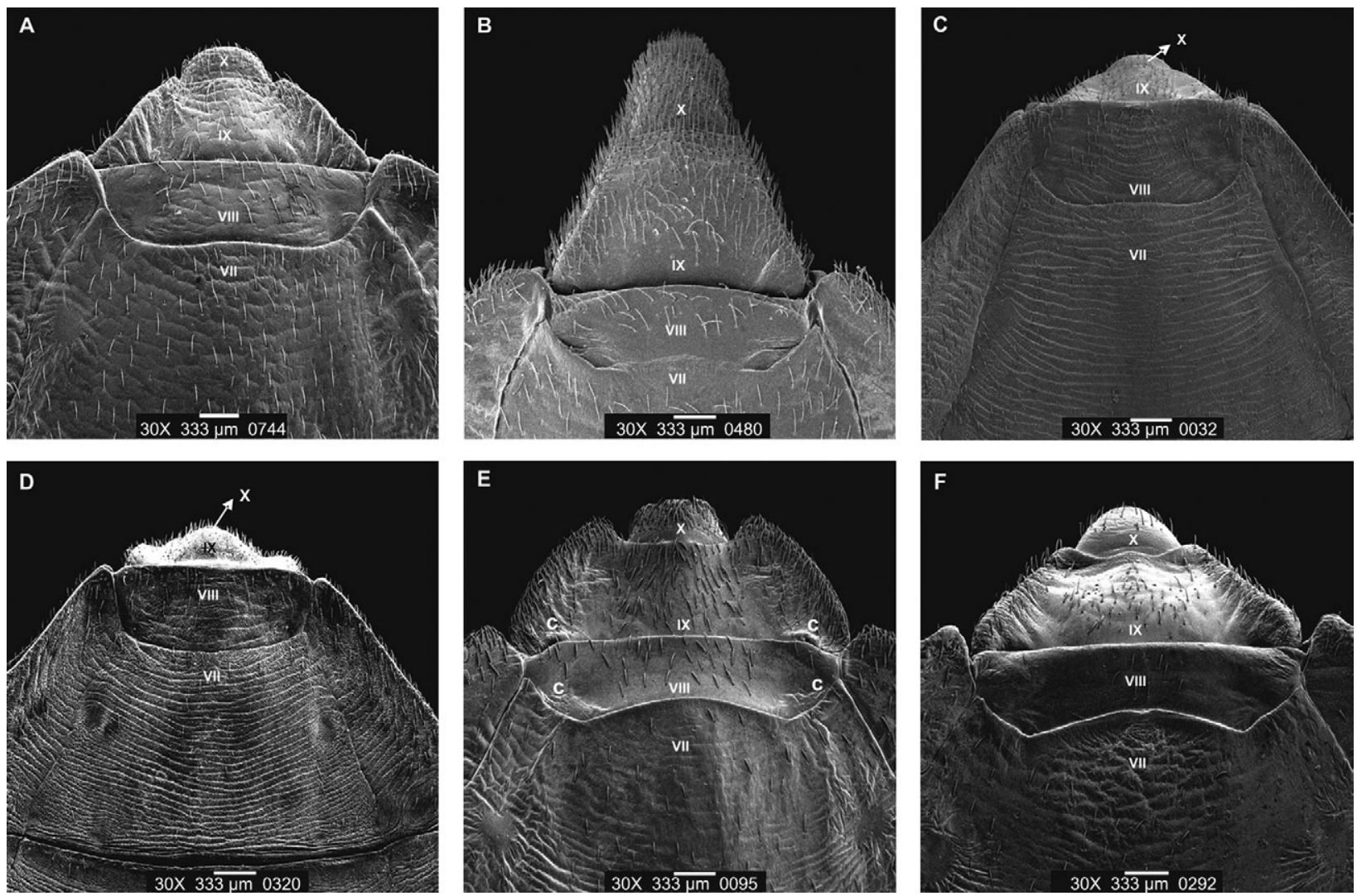

Fig. 1: female external genitalia of six species of triatomines by scanning electron microscopy, dorsal side. A: Panstrongylus herreri; B: Panstrongylus megistus; C: Rhodnius colombiensis; D: Rhodnius prolixus; E: Triatoma infestans; F: Triatoma vitticep; c: callosities; VII, VIII, IX tergites and X segment;

not observed in T. vitticeps. The dividing line between the IX tergite and $\mathrm{X}$ segment has three lobules in $T$. vitticeps, whereas in T. infestans the two lateral apices are raised (Fig. 1E, F).

Ventral side - By using SEM, it can be noted that the portion after the VII sternite, that constitutes external genitalia structures, is three times longer in $P$. megistus than in P. herreri. The sinuous, not the curved, portion of the VII sternite with the pair of VIII gonocoxites has greater curvature in $P$. megistus than in P. herreri.

The pair of VIII gonocoxites is about four times longer in P. megistus than in P. herreri. With respect to the widths of the bases, the ratio is about three to two, respectively. Although there is a difference in the length and the width of the VIII gonapophyses of these two species, the difference is not as evident as in the case of the VIII gonocoxites. A pair of IX gonocoxites can be observed in $P$. megistus but not in $P$. herreri (Fig. 2A, B).

In $R$. colombiensis, the VIII gonocoxites are large, whereas in $R$. prolixus they have a subtriangular shape. Although the VIII gonapophyses are subtriangular in both species of Rhodnius, they are thinner in $R$. prolixus. The final portion of the $\mathrm{X}$ segment is large in $R$. colombiensis and narrow in $R$. prolixus. In these two species, no difference was identified in the shape of the IX gonocoxites. On the other hand, the ventral view shows quite a noticeable difference in the IX gonocoxite: in $R$. colombiensis this structure has a curved border, while in $R$. prolixus it is a dilated lateral border (Fig. 2E, F).

The dividing line between the VII sternite and the pair of VIII gonocoxites has higher curvature in T. vitticeps than in T. infestans. Although the shape of the VIII gonocoxite is similar in both species, they are larger in $T$. infestans. The VIII gonapophyses also present a triangular shape, but they are more elongated in T. infestans than in T. vitticeps. The ventral view also clearly shows the lateral expansions of the IX sternite referred to earlier in the dorsal side of $T$. infestans. In addition, this species presents a straight final portion of the $\mathrm{X}$ segment, whereas the same portion is curved in T. vitticeps (Fig. 2F, G).

Lateral side - SEM observation of the lateral view also shows a difference between the VIII gonocoxites of $P$. megistus and P. herreri, the former having triangular and much larger structures, while in the latter they are half-moon shaped. In these two species the VIII gonocoxites establish the connection with the IX and X segments (Fig. 3A, B).

The lateral view shows that in $R$. colombiensis and $R$. prolixus the IX and X segments are inflected towards the ventral portion, indicating an abrupt termination in 

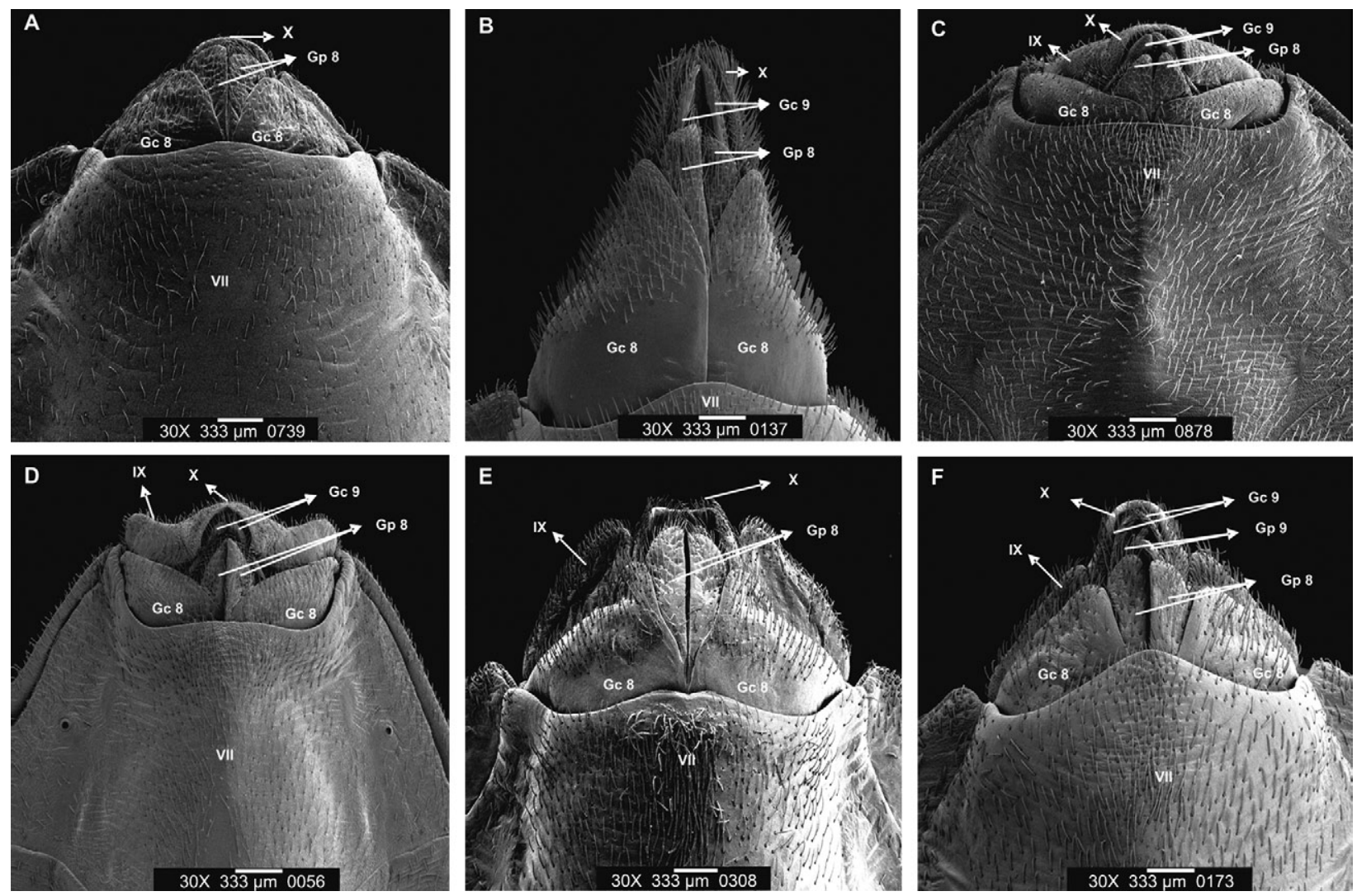

Fig. 2: female external genitalia of six species of triatomines by scanning electron microscopy, ventral side. A: Panstrongylus herreri; B: Panstrongylus megistus; C: Rhodnius colombiensis; D: Rhodnius prolixus; E: Triatoma infestans; F: Triatoma vitticeps; Gc8: gonocoxite VIII; Gc9: gonocoxite IX; Gp8: gonapophyse VIII; Gp9: gonapophyse; IX, VII and IX sternites and X segment.

macroscopic observation, as mentioned earlier. In these two species of Rhodnius, the VIII gonocoxites are limited to the IX and X segments (Fig. 3C, D).

Also in the lateral view, T. infestans and T. vitticeps differ in the way that the IX and X segments are disposed. In the former, they are in a flat position, whereas in the latter they are ventrally curved, although not as much as in the case of $R$. colombiensis and $R$. prolixus. In the two species of Triatoma, it is noted that the VIII gonocoxite is limited to the IX segment and is not seen on the $\mathrm{X}$ segment (Fig. 3E, F).

Posterior side - Observation of the female genitalia segments in samples positioned at an angle of $90^{\circ}$ by SEM reveals that these segments are larger in $P$. megistus than in P. herreri. The VIII gonocoxites of the latter are distinctly wider and shorter than those of the former, which are longer and narrower. The VIII gonapophyses of $P$. megistus are external and exceed the final portion of the X segment. In P. herreri, the VIII gonapophyses have a triangular shape, which is different from P. megistus, which has them elongated. The IX gonocoxites are visible in $P$. herreri but not in $P$. megistus (Fig. 4A, B).

In $R$. colombiensis and $R$. prolixus, the posterior view, also at $90^{\circ}$, shows that the IX and X segments are not separated as in P. herrreri, P. megistus and T. vitti- ceps but that there is a shallow dividing line. Therefore, the IX and X segments look like a single piece whose shape resembles an equilateral triangle in $R$. prolixus and an isosceles triangle in $R$. colombiensis. At the terminal parts of the VIII tergite, between the VII and IX segments and the VIII gonocoxite, there are $1+1$ external appendices in $R$. colombiensis and in $R$. prolixus these structures are smaller and not exteriorized. In the posterior view there is no difference between the VIII gonocoxites of these two species, but the VIII gonapophyses are larger in $R$. prolixus (Fig. 4C, D).

In T. infestans, the IX and X segments appear linked on the central portion and separated on the lateral sides. In contrast, they only appear separated in $T$. vitticeps. Both the VIII gonocoxite and VIII gonapophyse are almost triangular in the two species of Triatoma but larger in T. vitticeps (Fig. 1E, F).

\section{DISCUSSION}

Lent (1948), while describing the female genitalia of $R$. prolixus as observed by optical microscopy, suggested that this structure consists of the VII sternite, the anterior, median and posterior gonapophyses and the terminal segments (IX and X).

Abalos and Wygodzinsky (1951) used optical microscopy to describe the female genitalia of 11 species of 

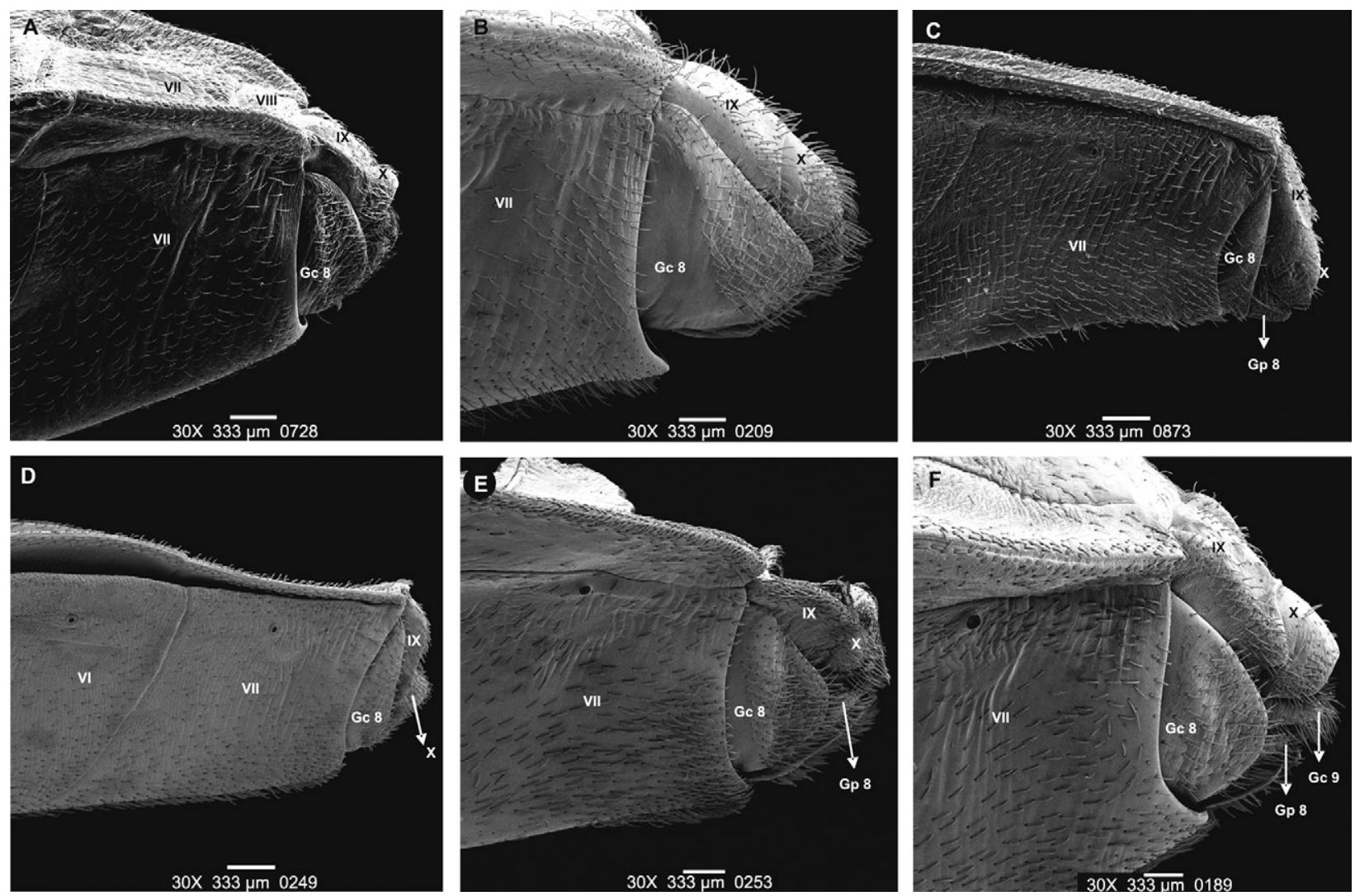

Fig. 3: female external genitalia of six species of triatomines by scanning electron microscopy, lateral side. A: Panstrongylus herreri; B: Panstrongylus megistus; C: Rhodnius colombiensis; D: Rhodnius prolixus; E: Triatoma infestans; F: Triatoma vitticeps; Gc8: gonocoxite VIII; Gc9: gonocoxite IX; Gp8: gonapophyse VIII; VI and VII sternites and VII, VIII, IX tergites and X segment.

Triatoma, three of Panstrongylus and one Psammolestes coreodes. These descriptions revealed some species of Triatoma that were alike with respect to the shape of the gonapophyses and other species that were different in this aspect. The researchers examined P. megistus, Panstrongylus guentheri and Panstrongylus geniculatus; the first had more differences and the other two were similar to each other.

In this study by SEM, P. megistus appeared very different from $P$. herreri, as well as from the two species of Rhodnius and the two of Triatoma. This distinction was noted on the dorsal, ventral, lateral and posterior sides (Figs 1-4).

Lent and Jurberg (1969) studied the female genitalia of 10 species of Rhodnius by dissection and optical microscopy. These techniques allowed for the identification and schematic drawing of gonocoxites and gonapophyses. According to this study, it is acknowledged that the genitalia is constituted of the gonocoxites and the gonapophyses, with the IX gonocoxite and the IX gonapophyse being distinct in the 10 species of Rhodnius studied by the authors.

Sherlock and Serafim (1967), in the description of Triatoma lenti, characterise the female genitalia of this species by scheme. When Bérenger and Pluot-Sigwalt
(2002) revalidated Rhodnius amazonicus, they also carried out the characterization of the female genitalia of the same species, as well as of Rhodnius pictipes.

The study of the dorsal side of female genitalia of $P$. herreri and $P$. megistus carried out by SEM revealed that they present differences in the shape of the dividing line between the VII and VIII tergites, as well as in the length of the IX tergite and X segments (Fig. 1A, B). With regard to the ventral side, the differences between the two species can be noted in the shape of the dividing line between the VII sternite and the VIII gonocoxites, in the shape and size of the VIII gonapophyses. The IX gonocoxites are only visible in P. megistus (Fig. 2A, B). On the posterior side, $P$. herreri and P. megistus differ from each other in the length and the shape of the IX tergite and the X segment, in the shape of the VIII and IX gonocoxites and in the fact that the VIII gonapophyses are not external in P. megistus (Fig. 2A, B)

The female genitalia of $R$. colombiensis and $R$. prolixus, when observed from the dorsal portion by SEM, show differences regarding the shape of the line that separates the VII and VIII tergites and the configuration acquired by the IX tergite segment (Fig. 1C, D). On the ventral side there are differences in the shape of the VIII gonocoxites and the VIII gonapophyses, as well as in 

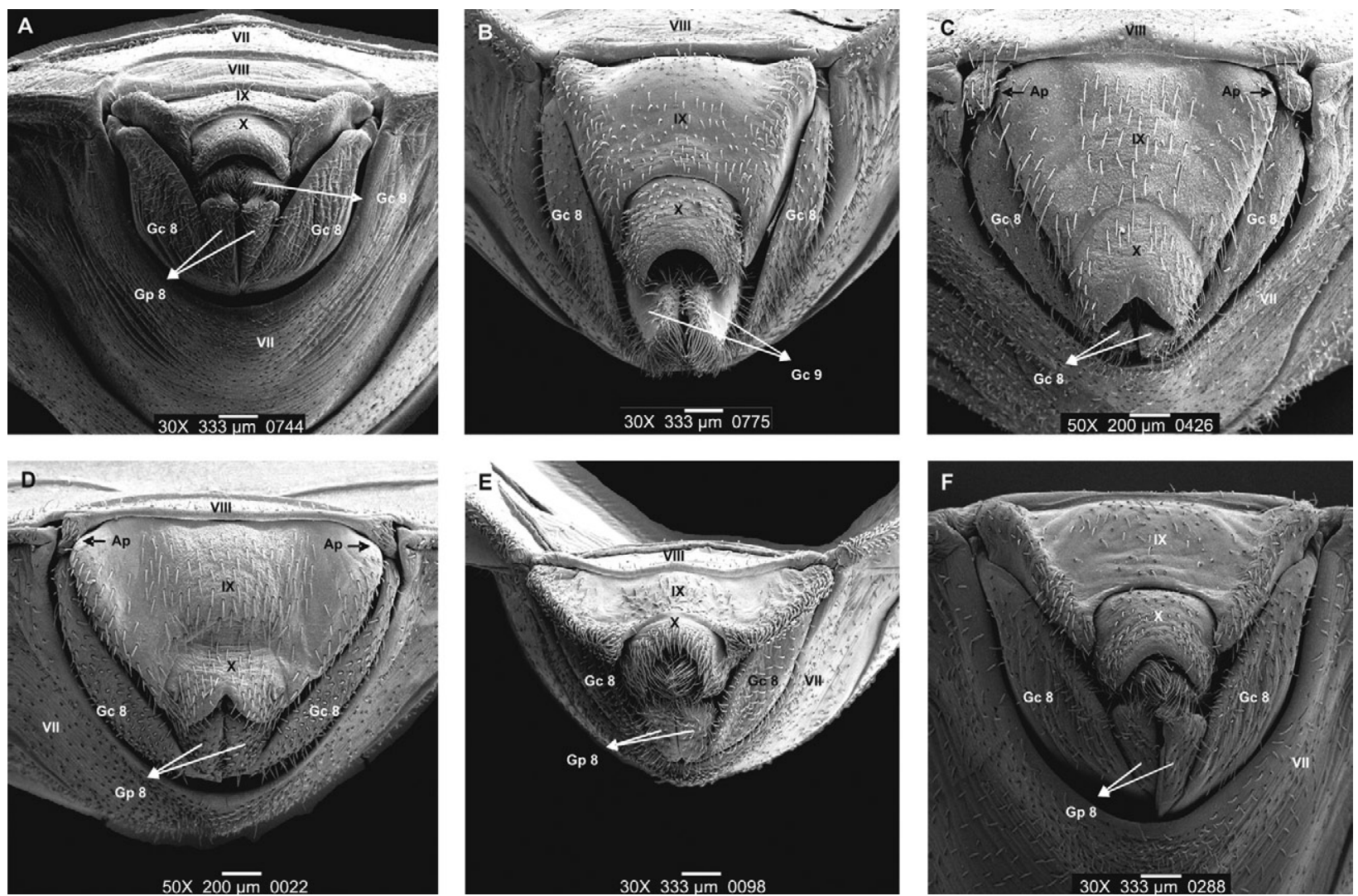

Fig. 4: female external genitalia of six species of triatomines by scanning electron microscopy, posterior side. A: Panstrongylus herreri; Ap: appendices; B: Panstrongylus megistus; C: Rhodnius colombiensis; D: Rhodnius prolixus; E: Triatoma infestans; F: Triatoma vitticeps; Gc8: gonocoxite VIII; Gc9: gonocoxite IX; Gp8: gonapophyse VIII; Gp9: gonapophyse; VII sternite and VII, VIII, IX tergites and X segment.

the shape of the IX and X sternites (Fig. 2C, D). Finally, from the posterior view a pair of appendices of the VII tergite is external in $R$. colombiensis but not in R. prolixus. Other differences are the shape of the IX segment and the size of the VIII gonapophyses (Fig. 4C, D).

$T$. infestans and $T$. vitticeps can be distinguished by means of the female genitalia observed on the dorsal side by scanning, considering that the first species presents $2+2$ callosities placed in the VIII and IX tergite segments, whereas there are no such callosities in the second. Another point of distinction is the shape of the IX tergite and the X segment (Fig. 1E, F). From the ventral view a difference can be noted in the shape of the dividing line between the VII sternites and the VIII gonocoxites, as well as in the size of the VIII gonocoxites and VIII gonapophyses and in the shape of the X segments (Fig. 2E, F). The posterior view shows differences in the size and shape of the IX tergite and the X segment and also in the size of the VIII gonocoxites and the VIII gonapophyses (Fig. 4E, F).

In brief, it was noted that female genitalia of $P$. herreri and $P$. megistus present four distinct elements on the dorsal side, three on the ventral side, one on the lateral side and three on the posterior side (Figs 1-4).

Similarly, between $R$. colombiensis and $R$. prolixus there are three distinct characters on the dorsal side, three on the ventral side and four on the posterior side (Figs 1, 2, 4).

$T$. infestans and T. vitticeps distinguish each other by female genitalia in four characters on the dorsal side, four on the ventral side, two on the lateral side and four on the posterior side (Figs 1, 2, 4). For the six species studied, there was a total of 11 distinct characters on the dorsal side, 10 on the ventral side, three on the lateral side and 11 on the posterior side (Figs 1-4).

Another characteristic that is visible in the dorsal, ventral, lateral and posterior view of $P$. megistus is a larger quantity of sensilla when compared to the same segments of $P$. herrerri. In $R$. colombiensis, the sensilla are uniformly distributed, but the same does not occur in $R$. prolixus in the ventral view. T. infestans shows more sensillae on the dorsal side than $T$. vitticeps (Figs 1-4). This characteristic was noted earlier in 10 Rhodnius species by Lent and Jurberg (1969), as they had observed a large number of sensillae in the gonocoxite 9 .

This study of the female genitalia by scanning six species ( 2 of Panstrongylus, 2 of Rhodnius and 2 of Triatoma) shows that the description of such characters can be valuable for a more specific species definition, indicating that it can contribute to the phylogenetic and taxonomic study of the 140 species attributed to the subfamily Triatominae. 


\section{ACKNOWLEDGEMENTS}

To Dr. José Maria Soares Barata, Professor of the Faculdade de Saúde Pública/USP, who donated 136 colonies of 36 species of Triatominae to the Faculdade de Cências Farmacêuticas/ UNESP-Araraquara, and to Bento Gregório de Jesús, João Luiz Molina Gil and João Maurício Nóbrega Filho, who were responsible for the maintenance of the colonies from 1983-2007.

\section{REFERENCES}

Abalos JW, Wygodzinsky P 1951. Las Triatominae argentinas (Reduviidae: Hemiptera), Universidad Nacional de Tucuman, Argentina, $179 \mathrm{pp}$.

Bérenger JM, Pluot-Sigwalt D 2002. Rhodnius amazonicus Almeida, Santos \& Sposina, 1973, bona species, close to R. pictipes Stål, 1872 (Heteroptera: Reduviidae: Triatominae). Mem Inst Oswaldo Cruz 97: 73-77.

Costa J, Argolo A, Felix M 2006. Redescription of Triatoma melanica, Neiva \& Lent, 1941, new status (Hemiptera: Rediviidae: Triatominae). Zootaxa 1385: 47-58.

Costa J, Felix M 2007. Triatoma juazeirensis sp. nov. from the state of Bahia, Northeastern Brazil (Hemiptera: Reduviidae: Triatominae). Mem Inst Oswaldo Cruz 102: 87-90.

Galati EAB 2003. Morfologia e taxonomia. Morfologia, terminologia de adultos e identificação dos táxons da América. In EF Rangel, R Lainson, Flebotomíneos do Brasil, Fiocruz, Rio de Janeiro, p. 53-175.

Galvão C, Angulo VM 2006. Belminus corredori, a new specie of Bolboderini (Hemiptera: Reduviidae: Triatominae) form Santander, Colômbia. Zootaxa 1241: 61-68.

Jurberg J, Lent H, Galvão C 1998. The male genitalia and its importance in taxonomy. In RU Carcavallo, I Galíndez Girón, J Jurberg, H Lent (eds.), Atlas of Chagas' disease vectors in the Américas, vol. 1, Fiocruz, Rio de Janeiro, p. 85-106.

Lent H 1948. O gênero Rhodnius Stål, 1859 (Hemiptera: Reduviidae). Rev Bras Biol 8: 297-339.

Lent H, Jurberg J 1969. O gênero Rhodnius Stål, 1859, com um estudo sobre a genitália das espécies (Hemiptera: Reduviidae: Triatominae). Rev Bras Biol 29: 487-560.
Lent H, Wygodzinsky P 1979. Revision of the Triatominae (Hemiptera: Reduviidae) and their significance as vectors of Chagas disease. Bull Am Mus Nat Hist 163: 123-520.

Marcondes CB, Lozovei AL, Galati EAB, Taniguchi HH 1998. The usefulness of Bergmann's rule to the distinction of members of Lutzomyia intermedia species complex (Diptera: Psychodidae: Phlebotominae). Mem Inst Oswaldo Cruz 93: 363-364.

Moncayo A, Silveira AC 2009. Current epidemiological trends for Chagas disease in Latin America and future challenges in epidemiology, surveillance and health policy. Mem Inst Oswaldo Cruz 104 (Suppl. I): 17-30.

Papa AR, Jurberg J, Carcavallo RU, Cerqueira RL, Barata JMS 2002. Triatoma sherlocki sp. n. coletada na Bahia, Brasil (Hemiptera: Reduviidae: Triatominae). Entomol Vect 9: 133-146.

Rocha DS, Jurberg J, Rosa JA, Schaefer CW, Galvão C 2009. Description of eggs and instars of Triatoma baratai Carcavallo \& Jurberg, 2000 based on optical and scanning electron microscopy (Hemiptera: Reduviidae: Triatominae). Zootaxa 2064: 1-20.

Rosa JA, Barata JM, Barelli N 1995. Morphology of abdominal bristles determined by scanning electron microscopy in six species of Triatominae (Hemiptera: Reduviidae). Mem Inst Oswaldo Cruz 90: 487-488.

Rosa JA, Medeiros MP, Cilense M, Barata JMS 2005. Morphological study of the thorax of the nynphal instars of Triatoma arthurneivai Lent \& Martins (Hemiptera: Reduviidae: Triatominae). Rev Bras Entomol 49: 289-293.

Santos CM, Jurberg J, Galvão C, Rosa JA, Ceretti Júnior W, Barata JMS, Obara MT 2009. Comparative descriptions of eggs from three species of Rhodnius (Hemiptera: Reduviidae: Triatominae). Mem Inst Oswaldo Cruz 104: 1012-1018.

Sherlock IA, Serafim EM 1967. Triatoma lenti sp.n., Triatoma pessoai sp.n. e Triatoma bahiensis sp.n. do estado da Bahia, Brasil (Hemiptera: Reduviidae). Gaz Med Bahia 67: 75-92.

WHO - Word Health Organization 2007. Reporte del grupo de trabajo cientifico sobre la enfermedad de Chagas, World Health Organization on behalf of the Special Programme for Research and Training in Tropical Diseases, Argentina, 96 pp. 